\title{
The relationship between Iranian patients' perception of holistic care and satisfaction with nursing care
}

\author{
Sahar Rajabpour ${ }^{1}$, Masoud Rayyani ${ }^{2}$ and Parvin Mangolian shahrbabaki ${ }^{3 *}$
}

\begin{abstract}
Background: Holistic care is comprehensive care that emphasizes the interaction of human existential dimensions and has a significant role in accelerating the recovery process. Since nurses interact and communicate with patients more than other health care providers, the current study aimed to determine the Iranian patients' perceptions of holistic care and overall satisfaction with nursing care.

Methods: It is a descriptive-correlational study done on patients admitted to the oncology wards of hospitals in southeastern Iran. The holistic caring inventory and patient satisfaction instrument were used to measure the patients' perceptions of holistic care and their satisfaction, respectively. SPSS 19 was used to analyze the data.

Results: The results showed that there is a significant positive correlation between patients' perception of holistic care and overall satisfaction with nursing care $(P<0.01, r=032)$, which means that the higher the patients' perception of holistic care, the greater their overall satisfaction. Based on the regression model, type of hospital, Patient's perception of holistic care, education, previous experience of hospitalization, age and marriage are respectively predictors of overall satisfaction with nursing care $(P<0.05)$.

Conclusion: The present study showed that patients' overall satisfaction with nursing care depends on holistic nursing care, meaning that nurses should pay attention to patients' physical, mental, emotional aspects and increase the quality of care.
\end{abstract}

Keywords: Perception, Patient, Holistic care, Satisfaction, Nursing care

\section{Background}

Holistic care is comprehensive care that addresses all physical, mental, emotional, spiritual, social and economic aspects of the patient [1]. According to the definition of American Holistic Nurses Association, holistic nursing includes the care that aim to improve or promote the integrity of a person from birth to death. Florence Nightingale expanded the holistic care to nursing [2] and emphasized that the nurse should use his or her hands, heart, and power of thought in creating a therapeutic environment for the care of the body, the mind and the soul of the patient [3]. Many other nursing

\footnotetext{
*Correspondence: mangolian167@gmail.com; mangolian167@yahoo.com; p_mangolian@kmu.ac.ir

${ }^{3}$ Nursing research center, Department of Critical Care Nursing, School of Nursing and Midwifery, Kerman University of Medical Sciences, Haft-bagh Highway, PO Box: 7716913555, Kerman, Iran

Full list of author information is available at the end of the article
}

theoreticians such as Rogers, Newman, and Parse have taken into account this caring approach [1]. Watson believes that the separation of mind, body, and spirit is impossible, and they have an undeniable effect on each other, and holistic care helps support both the physical and non-physical aspects of the individual [4]. holistic care is the source of the nursing profession and that conscientiousness, commitment, hope, and love were integral parts of this care $[5,6]$.

Despite all the effects of holistic care, the studies indicate weakness in the use of holistic care and limited attention of nurses to mental, psychological and spiritual dimensions of patients $[1,7,8]$. Also, few studies have been carried out on identifying patients' perceptions of holistic care [1, 2, 7, 9]. In most studies in developed countries where the patient's autonomy and rights are considered, nurses believe that the cares related to

(C) The Author(s). 2019 Open Access This article is distributed under the terms of the Creative Commons Attribution 4.0 International License (http://creativecommons.org/licenses/by/4.0/), which permits unrestricted use, distribution, and 
emotional or psychosocial needs of patients are more important [10], but in Iran, despite a small number of studies on caring behaviors of nurses, the results of studies indicate that nurses are more interested in physical aspects of care and often neglect the psychosocial dimensions of patients, leading to patients' dissatisfaction [11].

However, patients' satisfaction has been recognized as one of the five indicators in quality service delivery $[12,13]$. The quality of care as meeting physical needs by providing professional care, psychosocial support, satisfaction with care, and ensuring comprehensive care delivery to the patient $[14,15]$. Therefore, nurses need to be trained in holistic care skills.

In Iran, due to lack of nurses, lack of time, fatigue, the managers' interest in routine physical care, and the lack of emphasis on holistic care in nursing education, nurses may not have the necessary knowledge and skills for holistic care. For this reason, the patients are dissatisfied [12]. Peyrovi et al. (2013) reported that care for Iranian patients is focused on more physical aspects of care, while nurses are required to pay attention to other dimensions of care to provide comprehensive care [14]. It is very important and essential to study holistic nursing care for all aspects of human existential dimensions such as body, mind and soul, and the relationship between the viewpoint of patients as care recipients on holistic care and overall satisfaction with nursing care has not been studied in Iran. Therefore, the current study aimed to determine the relationship between overall patient satisfaction" and "holistic nursing care in hospitals of southeastern Iran.

\section{Methods}

\section{Study design}

It is a descriptive correlational study to investigate the relationship between the Iranian patients' perception of holistic care and overall satisfaction with nursing care in hospitals affiliated to Kerman University of Medical Sciences, which are the largest medical centers in southeastern Iran. This study lasted from July 2018 to October 2018.

\section{Instrument}

Three questionnaires were used to collect data. First, demographic information including age, sex, marital status, level of education, employment status, economic status, length of stay at the hospital, hospitalization frequency, previous history of hospitalization and type of hospital were collected through a questionnaire that was developed by the authors and approved by 7 faculty member of nursing (Additional file 1). The participants' perceptions of holistic care were taken by the holistic caring inventory ( $\mathrm{HCI})$. The holistic caring inventory was developed by Latham (1988) and instrument was evaluated by Latham (1996) in a study examining predictors of patient outcomes following caring interactions with nurses $[15,16]$. This instrument includes 40 items in scaled measures the strongly disagree (score 1), disagree (score 2), agree (score 3), strongly agree (score 4). The minimum score for a holistic caring inventory is 40, and the maximum score is 160. A higher score indicates a higher perception, so score below 80 shows poor perception, between 80 and 120 is the moderate perception and above 120 is high perception. The questionnaire was measured by Gardner \& Wheeler [15]. Cronbach's alpha coefficient has been reported to be 0.88 . The retest reliability coefficient was 0.89 . The construct validity of this scale was 0.83 by factor analysis, which indicates the high external validity of the test. Also, the correlation of items with the total test was reported to be higher than $0.50[15,16]$.

Finally, patient satisfaction instrument (PSI) was used to assess the satisfaction of participants with nursing care. Risser developed patient satisfaction instrument to evaluate the satisfaction of patients with nursing care [17], and Hinshaw, Scofield and Atwood corrected it [18]. The questionnaire includes 25 items in scaled measures including totally agree (score 5), agree (score 4), I am not sure (score 3), disagree (score 2) and totally disagree (score 1) with a minimum score of 25 and a maximum score of 125 . The scores of all the items were added and then divided by 25 to calculate the mean satisfaction of the patient. A score below 58 shows dissatisfaction, between 58 and 92 is the moderate satisfaction and above 92 is complete satisfaction. The validity of this tool was determined through content validity in a study carried out at hospitals affiliated to Iran University of Medical Sciences in 2013 [14]. Also, the reliability of the tool was estimated to be 0.9 using Cronbach's alpha coefficient in a study conducted in Iran Nursing and Midwifery Faculty in 2007 [12]. The researcher reevaluated the validity and reliability, and the Cronbach's alpha coefficient was 0.90 . Also, the content validity index was used to determine the content validity of the questionnaire and the validity of the questionnaire with a value of 0.99 was confirmed.

\section{Sampling and data collection}

To determine the sample size, according to previous studies and correlation coefficient (0.14), 95\% confidence and $90 \%$ test power, 90 samples were calculated, but to eliminate the possibility of loss of samples, 100 eligible patients admitted in the oncology wards were selected $[19,20]$.

After obtaining the permission of the Ethics Committee as well as permits and a letter of introduction from the Faculty of Nursing, Midwifery and Healthcare Centers, at first, two hospitals were considered similar in terms of 
population covered, number of nurses and patients. Then, all eligible patients who were admitted from 3 days or more in the oncology wards, were entered in the study to obtain the desired sample size. Because the shift nurses are in circulation, all patients have been cared by several nurses. The inclusion criteria included over the age of 18 , the fluency in the Persian language, the length of stay from 3 days and more in the ward, no emergency medical status, and the signed consent. The sampling lasted from July 27 to October 5 , and patients who did not have the consent to enter the study or were physically and mentally not able to complete the questionnaire were excluded. The data collection was done by the first researcher.

\section{Data analysis}

In this study, descriptive and inferential statistics were used to analyze the data. The software used in this study was SPSS 19. Descriptive statistics (frequency, percentage, mean, and standard deviation) was used to describe the demographic and underlying characteristics of the research units and the mean scores of perception of the holistic care and satisfaction. The Pearson correlation coefficient was used to assess the relationship between the mean scores of patients' perception of holistic care and overall satisfaction with nursing care because data were in normal distribution. Pearson, T-test, analysis of variance and Spearman tests were used to assess the relationship among the scores of patients' perception of holistic care, overall satisfaction, and demographic variables. Univariate and multivariate logistic regression was used to examine the data more accurately.

\section{Results}

According to the results of this study, of the 100 participants [50 patients from each hospital], 56\% were female, $76 \%$ were married, a majority (37\%) were aged between 40 and 45 years, most of them (88\%) had bachelor and lower degrees and most of them [91\%] were employed, $47 \%$ were economically in middle class $(10,000,000-30$, 000,000 Rials), and $61 \%$ of participants were admitted for the first time. Of the 39 patients who have experienced a hospitalization, only $28 \%$ stated they had a good experience of being hospitalized, and $72 \%$ had an unpleasant and negative attitude towards hospitalization (Table 1).

The results showed that the mean score of patients' perception of holistic care and overall satisfaction was $91 \pm 3.1$ and $89 \pm 3.8$, respectively. Therefore, according to mean scores, the patients' perceptions of holistic care are slightly higher than average [80], and the level of overall satisfaction is moderate (between 58 and 92). According to the data, there is a significant positive correlation between the patient's perception of holistic care and overall satisfaction with nursing care $(P=0.006$,
Table 1 Demographic characteristic of the patients

\begin{tabular}{|c|c|c|c|}
\hline Variables & & Frequency & Percentage \\
\hline \multirow[t]{2}{*}{ Sex } & Female & 56 & 56 \\
\hline & Male & 44 & 44 \\
\hline \multirow[t]{4}{*}{ Education } & $\mathrm{PhD}$ & 2 & 2 \\
\hline & Masters & 10 & 10 \\
\hline & Bachelor & 44 & 44 \\
\hline & Lower than bachelor & 44 & 44 \\
\hline \multirow[t]{2}{*}{ Marital status } & Married & 76 & 76 \\
\hline & Single & 24 & 24 \\
\hline \multirow[t]{6}{*}{ Age } & $20-25$ & 4 & 4 \\
\hline & $25-30$ & 10 & 10 \\
\hline & $30-35$ & 12 & 12 \\
\hline & $35-40$ & 12 & 12 \\
\hline & $40-45$ & 37 & 37 \\
\hline & 45 years up & 25 & 25 \\
\hline \multirow[t]{2}{*}{ Employment status } & Unemployed & 9 & 9 \\
\hline & Employed & 91 & 91 \\
\hline \multirow[t]{3}{*}{ Monthly income } & $\begin{array}{l}\text { Higher than 30,000,000 } \\
\text { Rials }\end{array}$ & 12 & 12 \\
\hline & $\begin{array}{l}\text { 10,000,000-30,000,000 } \\
\text { Rials }\end{array}$ & 47 & 47 \\
\hline & Less than $10,000,000$ Rials & 41 & 41 \\
\hline \multirow{3}{*}{$\begin{array}{l}\text { Duration of } \\
\text { admission }\end{array}$} & Less than a week & 48 & 48 \\
\hline & A week & 26 & 26 \\
\hline & More than a week & 26 & 26 \\
\hline \multirow[t]{3}{*}{ Admission times } & First time & 61 & 61 \\
\hline & $\begin{array}{l}\text { The second and } \\
\text { third times }\end{array}$ & 32 & 32 \\
\hline & $\begin{array}{l}\text { More than the third } \\
\text { time }\end{array}$ & 7 & 7 \\
\hline \multirow{2}{*}{$\begin{array}{l}\text { Previous experience } \\
\text { of hospitalization }\end{array}$} & Positive & 11 & 11 \\
\hline & Negative & 28 & 28 \\
\hline \multirow[t]{2}{*}{ Type of hospital } & Number 1 & 50 & 50 \\
\hline & Number 2 & 50 & 50 \\
\hline
\end{tabular}

$r=0.32$ ). Thus, with increasing patients' perception, their level of overall satisfaction increases. The value of $(0.32)$ suggests that the patients' perception of holistic care explains the $10 \%$ variance of satisfaction (Table 2).

Based on the results, there is a significant positive correlation between age and the patient's perception of holistic care $(p<0.01, r=0.29)$. As age grows, perceptions of holistic care increase. There is a significant relationship between the type of hospital and perceptions of holistic care $(P=0.001)$. Thus, perception of holistic care is higher in patients hospitalized at hospital No. 2. Also, there is a significant relationship among marriage, previous history of hospitalization, education and the patients' perception of holistic care $(P<0.05)$. Thus, 
Table 2 Correlation between Patient's perception of holistic care and overall patient satisfaction

\begin{tabular}{llllll}
\hline Variable & N & Mean & SD & Kolmogorov-smirnov test & Pearson correlation test \\
\hline Patients' perceptions of holistic care & 100 & 91 & 3.1 & 0.56 & $r=0.32$ \\
Overall Patient Satisfaction & 100 & 89 & 3.8 & 0.61 & $P=0.006$
\end{tabular}

married people, those with a previously positive history of hospitalization and those with the increase in education had a higher perception of holistic care. There is no significant relationship among monthly income, length of stay at the hospital and the admission frequency of participants with their perception of holistic care.

Based on the results, there is a significant relationship between the type of hospital and overall satisfaction with nursing care $(P=0.002)$. Thus, overall satisfaction was higher in hospital No. 2. There is a significant relationship between the history of admission, education and overall satisfaction with nursing care $(P<0.05)$. Thus, people with a positive history of hospitalization and those with the increase in education had a higher degree of overall satisfaction. According to the results, there is not a significant relationship among the economic status, length of stay at the hospital, hospitalization frequency and age with overall satisfaction.

Univariate logistic regression showed that there was a significant difference between education, employment status, marital status, previous experience, type of hospital with overall satisfaction. In order to eliminate confounding effects of independent variables and to investigate the predictors of satisfaction, all variables were entered into multivariate logistic regression model by Forward stepwise method (Likelihood Ratio). The results showed that education, employment status, marital status, previous experience and type of hospital was significantly correlated with overall satisfaction. In other words, those with $\mathrm{PhD}$, Masters, and Bachelor degrees were more satisfied than those with less education. Married people were more satisfied than single people. Employees were more satisfied than non-employees. Patients with positive experience of hospitalization were more satisfied than those with negative experience, and patients with hospital number 2 were more satisfied than hospital No. 1 (Table 3).

\section{Discussion}

The current study was done on patients' perception of holistic care, and overall satisfaction with nursing care, which showed that holistic nursing care would have an effective role in identifying the different needs of patients and their overall satisfaction with nursing care.

According to the results, the patients' perception of holistic care is slightly higher than average. In line with these results Wolf et al.(1998) and Loh (2006) showed that patients' perceptions of holistic care were at the moderate and higher level [21, 22]. In a different result, the study by Parvan et al. (2014) indicated that the majority of patients considered the quality of care in three psychosocial, physical and communication dimensions undesirable [23]. The possible reason for this difference with our study is that patients consider mostly the physical aspects of care, and due to lack of knowledge, they cannot accurately assess the competencies of nurses and believe that nurses are not able to predict and meet their needs. On the other hand, lack of human resources, lack of time, and reduced knowledge of nurses about holistic caring can also be other reasons for this difference.

The results showed that the mean score of patients' overall satisfaction with nursing care was at a moderate level. The study of Gholjeh et al. (2014) is consistent with the present study [24]. It seems the patients are satisfied when they feel pleasant and relaxed with nursing cares. It is not realized unless they accept nurses emotionally and rationally. The studies by Khezri et al. (2015) and Nayeri et al. (2010) with different results showed that the majority of patients were dissatisfied with the services provided by nurses. They mentioned the reasons for patients' dissatisfaction with nursing care such as the lack of nurses in therapeutic centers, lack of time, fatigue, high numbers of patients, the managers' interest in routine physical care, and the lack of control over the care process and training $[25,26]$.

In this study, there was a significant positive correlation between the patients' perception of holistic care and their overall satisfaction with nursing care and based on the regression model, the patients' perception is a strong predictor for overall satisfaction. Therefore, patients' level of perception increased with increasing overall satisfaction. In similar results, the researchers showed that patients who were more likely to observe and understand nursing care had higher levels of satisfaction with care. They showed that the implementation of a holistic care program would increase patients' satisfaction with nursing care. They found that nurses' behavior was fully observed by patients and patients judged the care at all times [12, 15, 21, 24]. Patients are less worried about the technical competence of nurses. In fact, recipients of health care want to receive nursing care from a nurse who listen to them and addresses their particular problems and understands them well [27-29].

Based on the results, it was observed that there is a significant relationship between the type of hospital with patients' perception of holistic care and overall satisfaction with nursing care. The regression model also 
Table 3 Univariate and multivariate regression model for all variables and overall satisfaction

\begin{tabular}{|c|c|c|c|c|c|c|c|}
\hline \multirow[t]{2}{*}{ Variable } & & \multicolumn{3}{|c|}{ Univariate logistic regression } & \multicolumn{3}{|c|}{ Multivariate logistic regression } \\
\hline & & Odds ratio & Confidence Interval & $P$ value & Odds ratio & Confidence Interval & $P$ value \\
\hline \multirow[t]{6}{*}{ Age } & $20-25$ & 1 & & & & & \\
\hline & $25-30$ & 1.04 & $1.29-0.91$ & 0.35 & & & \\
\hline & $30-35$ & 0.82 & $1.45-0.22$ & 0.28 & & & \\
\hline & $35-40$ & 1.63 & $1.17-0.87$ & 0.41 & & & \\
\hline & $40-45$ & 1.24 & $1.41-0.65$ & 0.74 & & & \\
\hline & 45 years up & 1.53 & $1.12-0.83$ & 0.63 & & & \\
\hline \multirow[t]{2}{*}{ Sex } & Male & 1 & & & & & \\
\hline & Female & 1.32 & $0.71-2.41$ & 0.51 & & & \\
\hline \multirow[t]{4}{*}{ Education } & $\mathrm{PhD}$ & 1 & & & 1 & & \\
\hline & Masters & 1.22 & $1.59-0.91$ & 0.01 & 1.57 & $1.07-0.97$ & $0.001>$ \\
\hline & Bachelor & 1.09 & $1.15-0.84$ & 0.02 & 1.31 & $2.85-0.29$ & $0.001>$ \\
\hline & Lower than bachelor & 0.95 & $1.09-0.82$ & 0.04 & 0.84 & $1.24-0.91$ & $0.001>$ \\
\hline \multirow[t]{2}{*}{ Marital status } & Married & 1 & & & 1 & & \\
\hline & Single & 0.92 & $0.88-0.81$ & 0.04 & 0.97 & $0.86-0.74$ & 0.005 \\
\hline \multirow[t]{2}{*}{ Employment status } & Unemployed & 1 & & & 1 & & \\
\hline & Employed & 2.11 & $2.92-0.79$ & 0.02 & 3.94 & $2.61-1.31$ & 0.001 \\
\hline \multirow[t]{3}{*}{ Monthly income } & $30,000,000$ Rials $\geq$ & 1 & & & & & \\
\hline & $10,000,000-30,000,000$ Rials & 1.38 & $2.09-0.47$ & 0.32 & & & \\
\hline & $\geq 10,000,000$ Rials & 0.79 & $1.85-0.24$ & 0.43 & & & \\
\hline \multirow[t]{2}{*}{ Duration of admission } & A week & 1 & & & & & \\
\hline & More than a week & 1.76 & $1.09-0.51$ & 0.69 & & & \\
\hline \multirow[t]{3}{*}{ Admission times } & First time & 1 & & & & & \\
\hline & The second and third times & 1.8 & $2.12-0.64$ & 0.53 & & & \\
\hline & More than the third time & 1.22 & $2.04-0.3$ & 0.88 & & & \\
\hline \multirow[t]{2}{*}{ Previous experience } & Positive & 1 & & & 1 & & \\
\hline & Negative & 0.51 & $0.79-0.1$ & 0.03 & 0.58 & $0.24-0.01$ & 0.004 \\
\hline \multirow[t]{2}{*}{ Type of hospital } & Number 1 & 1 & & & 1 & & \\
\hline & Number 2 & 3.24 & $2.9-0.89$ & 0.01 & 4.05 & $3.81-1.21$ & 0.003 \\
\hline
\end{tabular}

confirmed this finding, in other words, the working environment is a strong predictor of overall satisfaction. These results indicate that the type of hospital and working environment play an essential role in nursing care, perception of holistic care and satisfaction of patients. In confirming this issue, a number of studies reported that many factors such as working environment, in-service training, management quality and timeliness affects the quality of nursing care and patients' satisfaction [30, 31].

Results showed with increasing education, patients' overall satisfaction increase and based on the regression model, level of education is a predictor for overall satisfaction. The study of Nemati et al. (2014) reported a significant difference between the levels of satisfaction with clinical services regarding education. The satisfaction has increased with an increase in the level of education
[32]. In the study of Zakeri-moghadam and Sadeghi (2013), there was a direct significant relationship between the level of education of patients and their satisfaction with nursing services. The lowest satisfaction was related to less educated patients, and the highest satisfaction was observed in patients with a diploma and higher education [33]. In a different study, Joolaee et al. (2014) showed the level of satisfaction of patients with lower education was higher than that of educated patients [34]. The possible reason for this difference with our study can be because less educated patients have a low perception of the problems and job descriptions of nurses or the satisfaction of patients might not have related to nursing care behaviors. Other factors such as structural, intra-organizational and extra-organizational factors could affect this satisfaction. The higher the expectation of people from the nurses and their care, the 
lower their adaptation to existing realities and, consequently, the lower their satisfaction. Because educated people have more social communications and more access to information resources, they observe existing shortages more clearly, and they are usually less satisfied.

According to the results, patients who had a previous positive experience of hospitalization were more satisfied and based on the regression model; the previous experience of hospitalization is a predictor for overall satisfaction. It seems that patients with a history of previous hospitalization recognize the health center and adjuste their expectations and are more satisfied. These findings were confirmed by a number of studies [27]. In the study of Khezri et al. (2015) there was no significant relationship between patient's satisfaction and previous history of hospitalization [25].

Result of this study showed that there is a statistically significant relationship between age and overall satisfaction. Higher satisfaction with care was observed in older patients and age included satisfaction predictors. Several studies reported a significant difference between the levels of satisfaction with clinical services regarding age. The satisfaction has increased with an increase in age $[31,35,36]$. In different results, in the study of Williams (1998), there was no significant relationship among age and satisfaction with nursing care [19]. Also, married patients had a higher overall satisfaction and that is a predictor for satisfaction. In confirmation with these results, numerous studies have indicated that married people have more satisfaction because they have more experience and understanding of nursing care [36].

This study encountered a limitation. In this study was only a single measurement method that involved selfreport questionnaire as the sole measurement method.

\section{Conclusion}

Therefore, the hypothesis "there is a correlation between patients' perceptions of holistic care and their satisfaction with nursing care" is acknowledged, and this reflects the increasing need of today's societies for professional nurses and the expansion of nursing duties. Given that holistic care is a comprehensive care approach that affects all aspects of human as a whole, professional education of nursing students can play an important role in the development of competent nurses. In addition, nursing managers can provide a comprehensive view of the patient care through in-service training for staff. Since patients have the right of psychosocial and spiritual care in addition to physical one, paying attention to patients' opinions increases the quality and quantity of health care provided by the nursing community and patient's satisfaction. However, further studies are required on this scope.

\section{Supplementary information}

Supplementary information accompanies this paper at https://doi.org/10. 1186/s12912-019-0374-7.

Additional file 1. Is the English language versions of the demographic questionnaire developed and used in this study.

\section{Abbreviations}

HCl: Holistic Caring Inventory; PSI: Patient Satisfaction Instrument

\section{Acknowledgements}

The authors would like to extend their thanks and appreciation to the patients who participated in this study.

\section{Authors' contributions}

SR, MR and PM contributed to designing the study, SR collected the data, PM analyzed the data, and SR, MR and PM wrote the final report and manuscript. All the authors read and approved the version for submission.

\section{Funding}

This research received no specific grant from any funding agency in the public, commercial, or not-for-profit sector.

\section{Availability of data and materials}

Data are available by contacting the corresponding author.

\section{Ethics approval and consent to participate}

This study was approved by the Ethics Committee of Kerman University of Medical Sciences [IR.KMU.REC.1397.153]. The researcher gave oral and written information and obtained written informed consent from all participants before the interviews. Participation was voluntary, and the participants had the right to withdraw at any time.

Consent for publication

Not applicable.

\section{Competing interests}

The authors declare that they have no competing interests.

\section{Author details}

${ }^{1}$ Psychiatric Nursing, Ghaem Hospital, Bardsir, Iran. ${ }^{2}$ Community Health Nursing, Special Diseases Center, Kerman, Iran. ${ }^{3}$ Nursing research center, Department of Critical Care Nursing, School of Nursing and Midwifery, Kerman University of Medical Sciences, Haft-bagh Highway, PO Box: 7716913555, Kerman, Iran.

Received: 11 January 2019 Accepted: 10 October 2019

Published online: 26 October 2019

\section{References}

1. Zamanzadeh V, Jasemi M, Valizadeh L, Keogh B, Taleghani F. Effective factors in providing holistic care: a qualitative study. Indian J Palliat Care. 2015;21(2):214.

2. Aghebati N, Mohammadi E, Ahmadi F. The concept of nursing in holistic theories: an integrative review. Evidence Based Care. 2012;2(2):67-84.

3. Karami A, Farokhzadian J, Foroughameri G. Nurses' professional competency and organizational commitment: is it important for human resource management? PLoS One. 2017 Nov 8;12(11):e0187863.

4. Akram sadat $\mathrm{SH}$, Fatemeh A, Abdolhossein K, Abdolkarim B. Explanation of Meta paradigm of Human in Islamic Sources and Nursing Theories. Research Development in Nursing \& Midwifery. 2011;9:36-68.

5. Mollaoğlu M, Üstün E. Fatigue in multiple sclerosis patients. J Clin Nurs. 2009;18(9):1231-8.

6. Frisch NC. Standards of holistic nursing practice as guidelines for quality undergraduate nursing curricula. J Prof Nurs. 2003;19(6):382-6.

7. Daaleman TP, Usher BM, Williams SW, Rawlings J, Hanson LC. An exploratory study of spiritual care at the end of life. Ann Fam Med. 2008;6(5):406-11.

8. Robinson S. Holistic health promotion: putting the art into nurse education Nurse Educ Pract. 2007;7(3):173-80. 
9. Bahrami M. Do nurses provide holistic care to cancer patients? Iran J Nurs Midwifery Res. 2010;15(4):245.

10. Elhami S, Beygi K, Hooshirikha H, Ladab N, Cheraghian B, Sharifi Z. Career behavioral training program and understanding Patients' Care of nursing students in public sector. Jama. 2015;293(9):68-96.

11. Asadi S, Abadi R. Perceived organizational support and job involvement in the Iranian health care system: a case study of emergency room nurses in general hospitals. J Educ Health Promot. 2014;3.

12. Hajinezhad MS, Rafii F, Jafarjalal E, Haghani H. Relationship between nurse caring behaviors from patients' perspectives \& their satisfaction. Iran J Nurs. 2007;20(49):73-83.

13. Farahani MF, Shamsikhani S, Hezaveh MS. Patient satisfaction with nursing and medical care in hospitals affiliated to arak university of medical sciences in 2009. Nursing and midwifery studies. 2014;3(3).

14. Peyrovi H, Bahadori A, Ashghali-Farahani M, Haghani H. Comparison of inpatients' satisfaction with different domains of nursing care. Quarterly Journal of Nursing Management. 2013;2(1):59-66.

15. Gardner KG, Wheeler EC. Patients' perceptions of support. West J Nurs Res. 1987:9(1):115-31.

16. Watson J, editor. Assessing and measuring caring in nursing and health science. Springer Publishing Company; 2008.

17. Risser NL. Development of an instrument to measure patient satisfaction with nurses and nursing care in primary care settings. Nurs Res. 1975;24(1): 45-52.

18. Hinshaw A, Scofield R, Atwood J. 1981. Staff, patient, and cost outcomes of all- registered nurse staffing. J Nurs Adm. 1981;11(11-12):30-6.

19. Williams SA. The relationship of patients' perceptions of holistic nurse caring to satisfaction with nursing care. Essential Readings in Holistic Nursing. 1998;32.

20. Haghdoost A. Do You Want To Gain A Profound Insight Into Sample Size And Statistical Power. Iranian Journal Of Epidemiology. Jun 15. 2009;5(1):57-63).

21. Wolf ZR, Colahan M, Costello A, Warwick F, Ambrose MS, Giardino ER Relationship between nurse caring and patient satisfaction. Medsurg Nurs. 1998:7(2):99-106.

22. Loh KY. Exploring terminally ill patients' and their families' perceptions of holistic care in Malaysia. Int J Palliat Nurs. 2006;12(1):38-41.

23. Parvan K, Ebrahimi H, Zamanzadeh V, Seyedrasooly A, Dadkhah D, Jabarzadeh F. Empathy from the Nurses' viewpoint in teaching hospitals of Tabriz University of Medical Sciences. Iran J Caring Sci. 2014 Mar;3(1):29.

24. Gholjeh M, Dastoorpour M, Ghasemi A. The relationship between nursing care quality and patients satisfaction among hospitals affiliated to Zahedan University of Medical Sciences in 2014. Jorjani Biomedicine Journal. 2015; 3(1):68-81.

25. Khezri L, Ravanipour M, Jahanpour F, Mirzaee K. Assessment of patient satisfaction with nursing services provided in general wards of university hospitals in Bushehr 2012. Nvj. 2015;2:36-46.

26. Nayeri ND, Aghajani M. Patients' privacy and satisfaction in the emergency department: a descriptive analytical study. Nurs Ethics. 2010;17(2):167-77.

27. Madani G, Farzan A, Rabiee M. Patient satisfaction of medical and nursing services. Iran J Nurs Midwifery Res. 2010;8:9(3).

28. Shahrbabaki PM, Farokhzadian J, Hasanabadi Z, Hojjatoleslami S. The evaluation of the educational plan of breast self-examination of women referring to health centers. Procedia Soc Behav Sci. 2012;31:913-7.

29. Hatefi M, Tarjoman A, Borji M. Do religious coping and attachment to god affect perceived pain? Study of the elderly with chronic back pain in Iran. Relig Health. 2019 Jan;4:1-1.

30. Ebadzadeh MR, Nouhi E, Farokhzadian J, Mangolian SP. What is the supporting role of health care providers from the perspective of patients with renal allograft rejection? A qualitative study. Int J Health Plann Manag. 2019 Jan;34(1):338-45.

31. Mohammad MA. Healthcare service quality: towards a broad definition. Int J Health Care Qual Assur. 2013 Mar 15;26(3):203-19.

32. Nemati F, Mohammadnejad E, Tabatabaei A, Ehsani S, Sajjadi A, Hajiesmaeilpoor A. Satisfaction rate of hospitalized patients in teaching hospitals with presented services. Medical ethics. 2014;8(28):29-50.

33. Zakeri-moghadam M, Sadeghi S. Effects of comprehensive-care program on patients' satisfaction with trauma in emergency department. Cardiovascular Nursing Journal. 2013;2(3):54-62.

34. Joolaee S, Rasti F. Ghiyasvandian s, haghani h. patients'perceptions of caring behaviors in oncology settings. Iran J Nurs Midwifery Res. 2014;9(1):56-67.
35. Lee DS, Tu JV, Chong A, Alter DA. Patient satisfaction and its relationship with quality and outcomes of care after acute myocardial infarction. Circulation. 2008;118(19):1938-45.

36. Jenkinson C, Coulter A, Bruster S, Richards N, Chandola T. Patients' experiences and satisfaction with health care: results of a questionnaire study of specific aspects of care. Qual Saf Health Care. 2002 Dec 1;11(4): $335-9$

\section{Publisher's Note}

Springer Nature remains neutral with regard to jurisdictional claims in published maps and institutional affiliations.
Ready to submit your research? Choose BMC and benefit from:

- fast, convenient online submission

- thorough peer review by experienced researchers in your field

- rapid publication on acceptance

- support for research data, including large and complex data types

- gold Open Access which fosters wider collaboration and increased citations

- maximum visibility for your research: over $100 \mathrm{M}$ website views per year

At BMC, research is always in progress.

Learn more biomedcentral.com/submissions 